\title{
Retrieval of a Fish Hook from an Indian Flap Shell Turtle
}

\author{
Beenish Qureshi, Jasmeet Khosa*, Deepti Sharma and Kirandeep Kour Gill \\ Department of Veterinary Surgery \& Radiology, \\ Guru Angad Dev Veterinary and Animal Sciences University, Ludhiana, India \\ *Corresponding author
}

\section{A B S T R A C T}

\begin{tabular}{|l|}
\hline Ke y w o r d s \\
Turtle, Fish hook, \\
Radiography \\
\hline Article Info \\
\hline $\begin{array}{l}\text { Accepted: } \\
\text { 18 May 2020 } \\
\text { Available Online: } \\
\text { 10 June } 2020\end{array}$ \\
\hline \hline
\end{tabular}

\section{Introduction}

Indian flap shell turtle (Lissemys punctata) is a very common fresh water turtle found in India and it can be found fairly easily in ponds, steams, marshes, near our house during rainy season and in fish markets. They prefer quiet and stagnant waters with sand or mud as a substrate since they like to burrow. They have a soft leathery type of shell and they are called as flap shell because they have flaps on the plastron above their legs which cover their legs when they retract in the shell. Indian flap shell turtle is omnivorous, eating not only mollusks, insects, fish, amphibians, waterfowl and carrion, but aquatic plants as well (Vitt and Caldwell, 2009). The shell of $L$. punctata is believed to be of medicinal value in both China and India as the shell is burnt and ground with oil in China to treat certain types of skin diseases. In India, the shell is used to make a remedy believed to be a medicine for tuberculosis (Moll and Moll, 2004).

\section{Case report}

An adult-sized flap shell turtle of unknown age was presented to Department of Veterinary Surgery and Radiology, GADVASU with the history of protruding fish hook from its mouth. The turtle on clinical examination appeared bright and alert and was not making attempts to regurgitate. Assessment of skin turgor indicated it was adequately hydrated. On manipulation the hook seemed to be embedded inside the left corner of the mouth with a small portion of it 
protruding out. To determine the exact size and the location of the hook radiography was performed. The conscious turtle was placed horizontally on the table to prevent walking and neck was manually extended to get a clear radiograph which it gradually resisted. A dorsoventral radiograph confirmed a hook measuring $2.56 \mathrm{~cm}$ lodged inside the oral cavity with barb pointing orally (Fig.1). It was decided to attempt surgical removal of the fish hook.

The turtle was anaesthetized in a special gas chamber maintained on $2 \%$ isoflurane till it showed relaxation of its neck and limbs (Fig.2). Depth of anesthesia was monitored by evaluating toe/tail pinch response. With the turtle in recumbency, the neck was routinely scrubbed, and draped. Artery forcep was guided inside the oral cavity to approximately determine the position of hook as visibility was poor.

Incision was made over the desired area and considerable maneuvering and tearing of the mucosa was required to free up the hook before it could be pulled out through the incision. As diagnosed by radiography 2.56 $\mathrm{cm}$ approximately barbed hook was retrieved from the oral cavity of the turtle with no monofilament line attached to the eye (Fig. 3). After removal of hook the area was lavaged with sterile saline. As the incision was superficial enough no such suturing was done and the oral mucosa was left to heal by itself.

Postoperatively the turtle was kept in a dark, quiet tank where it recovered well from anesthesia. Treatment with enrofloxacin @ $10 \mathrm{mg} / \mathrm{kg}$ bwt was given for five days bid intramuscularly by stretching its hind limb. Meanwhile food/water was given as before and the turtle readily began voluntary feeding. The turtle recovered uneventfully without any complications in few days.

\section{Results and Discussion}

Foreign bodies in turtles and other water animals can vary from fish hooks, stones, to plastic material. Turtles are apparently able to sustain considerable injuries and still survive with hooks in the gastrointestinal tract. Hooks lodged in the gastrointestinal tract of turtles are sometimes expelled spontaneously and they are able to keep feeding normally (Alegre et al., 2006). Compared to the presence of hook alone turtles with a long monofilament attached to the hook exiting through the cloaca or mouth (Di Bello et al., 2006b) have a worse prognosis. However serious consequences such as esophagitis, stricture formation with resultant regurgitation, cellulitis, peritonitis and potentially death are likely after gastrointestinal perforation.

Surgical removal of the fish hook in this case was carried out as it was a recent ingestion and therefore less likely to have caused severe complications. Radiography was carried out to know the exact position and soft tissue involvement following the trauma due to fish hook entrapment. A number of anesthetic protocols are advocated for use in turtles. Premedication is not commonly used due to the fact that it prolongs the effect of injectable anesthetics due to the slow metabolism of turtles. Several methods of general anesthesia have been described including the use of IV anesthesia alone, gaseous anesthesia along or without intubation etc. (McArthur, 1996) IV induction followed by intubation is useful for aquatic turtles as they tend to breath-hold but due to reluctance of opening the mouth and less surgical space gaseous anesthesia without intubation was carried out. Anesthetic depth was considered adequate when the hind limb and tail did not respond to pinching. The reflex responses of a turtle are lost from head to tail and return in the reverse direction. 


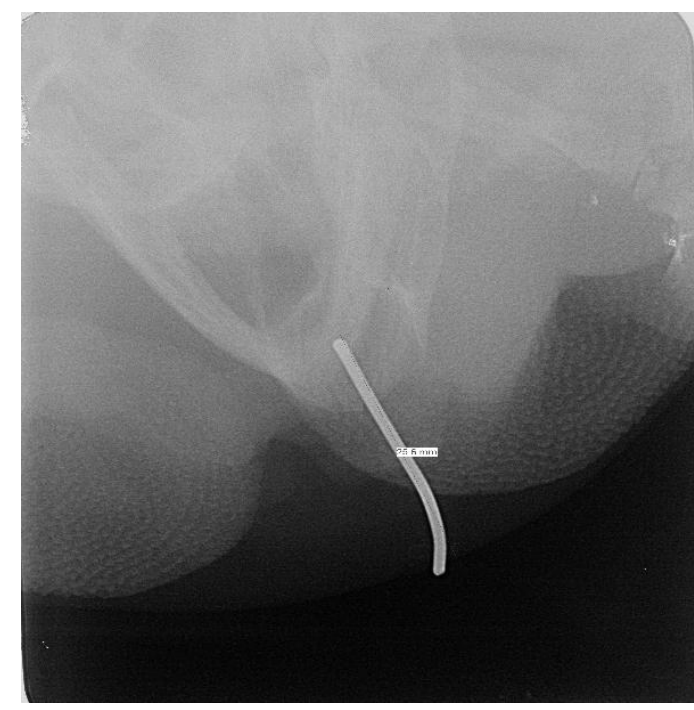

Fig.1 Dorsoventral radiograph of turtle revealing $2.56 \mathrm{~cm}$ hook inside oral cavity

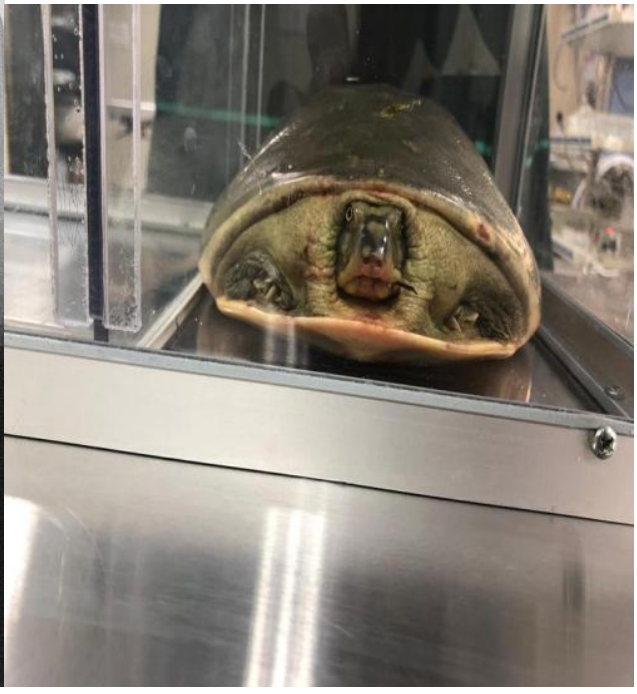

Fig.2 Anaesthetic induction of a turtle inside a gas chamber with $2 \%$ isoflurane

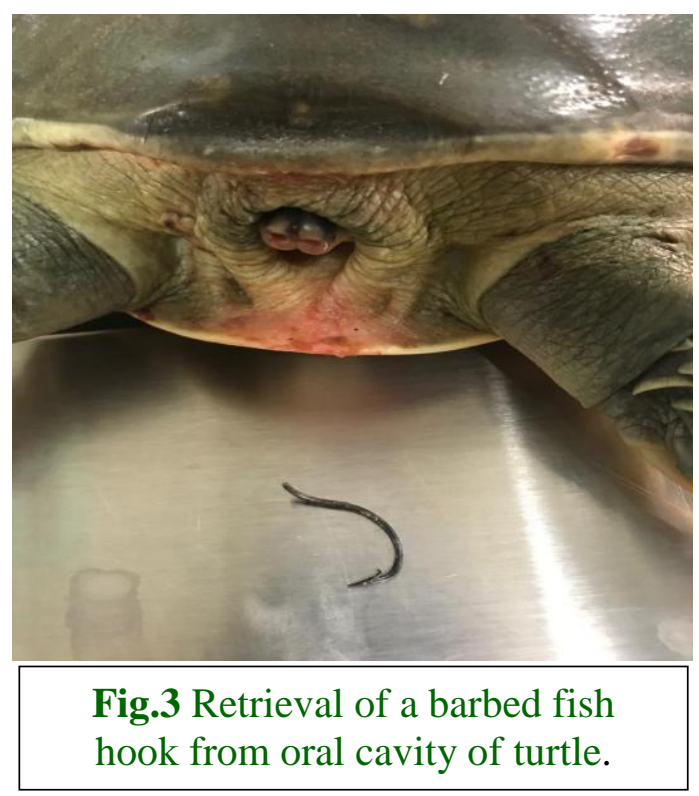

\section{References}

Alegre, F., M. Parga, C. Castillo, and S. Pont. (2006). Study on the long-term effect of hooks lodged in the mid-esophagus of sea turtles. Twenty-sixth Annual Symposium on Sea Turtle Biology and Conservation, 3-8 April, Creta, Greece, $234 \mathrm{pp}$
Di bello,A., C. Valastro, and F. Staffieri. (2006a). Surgical approach to the coelomic cavity through the axillary and inguinal regions in sea turtles. Journal of the American Veterinary Medical Association 228: 922-925.

McArthur S.Veterinary management of tortoises and turtles. Blackwell, Oxford, 1996; 8-11, 138-141 
Moll D, Moll E (2004). The Ecology, Exploitation, and Conservation of River Turtles. Oxford University Press. pp. 177-180.

Vitt, L.J., and Caldwell, J.P. (2009).
Herpetology: An Introductory Biology of Amphibians and Reptiles. Third Edition. Academic Press, Burlington, Massachusetts.

\section{How to cite this article:}

Beenish Qureshi, Jasmeet Khosa, Deepti Sharma and Kirandeep Kour Gill. 2020. Retrieval of a Fish Hook from an Indian Flap Shell Turtle. Int.J.Curr.Microbiol.App.Sci. 9(06): 1500-1503. doi: https://doi.org/10.20546/ijcmas.2020.906.184 